\title{
Interleukin-10 repletion suppresses pro-inflammatory cytokines and decreases liver pathology without altering viral replication in murine cytomegalovirus (MCMV)-infected IL-10 knockout mice
}

\author{
Yajarayma J. Tang-Feldman · G. Raymond Lochhead • \\ Stephanie R. Lochhead • Cindy Yu • \\ Claire Pomeroy
}

Received: 9 August 2010/Revised: 14 September 2010/Accepted: 15 September 2010/Published online: 5 October 2010 (C) The Author(s) 2010. This article is published with open access at Springerlink.com

\begin{abstract}
Objective and design To determine the role of interleukin-10 (IL-10) in protecting against the deleterious proinflammatory cytokine response to murine cytomegalovirus (MCMV), we studied the impact of IL-10 repletion in MCMV-infected IL-10 knockout (KO) mice.

Materials and methods IL-10 KO mice were infected with a sub-lethal dose of MCMV and treated daily with $5 \mu \mathrm{g}$ of mouse recombinant IL-10 (mrIL-10). Cytokine transcription, viral load, cytokine expression and liver histopathology were assessed in IL-10 treated and untreated mice.

Results mrIL-10 repletion suppressed the exaggerated pro-inflammatory cytokine response observed in IL-10 KO mice (vs. control) both systemically and at the organ level, without affecting viral load. Levels of IFN- $\gamma$ and TNF- $\alpha$ mRNA in livers of treated mice were $\sim 50-70$-fold lower than in untreated mice at day 5 post-infection $(p \leq 0.05)$. In spleens and sera, levels of IFN- $\gamma$ and IL- 6 were significantly lower in treated mice than in untreated mice at day 5-7 post-infection $(p \leq 0.05)$. IL-10 blunting of cytokine
\end{abstract}

Responsible Editor: Graham Wallace.

Y. J. Tang-Feldman $(\bowtie) \cdot$ G. R. Lochhead ·

S. R. Lochhead · C. Pomeroy $(\bowtie)$

Division of Infectious Diseases, Department of Internal

Medicine, University of California, Davis Health System,

4150 V St., Suite 500, Sacramento, CA 95817, USA

e-mail: yjtangfeldman@ucdavis.edu

C. Pomeroy

e-mail: Claire.pomeroy@ucdmc.ucdavis.edu

C. $\mathrm{Yu}$

Medical Pathology, Davis Health System,

University of California, Sacramento, CA 95817, USA responses was accompanied by attenuation of inflammation in livers of treated mice.

Conclusions Repletion of IL-10 modulates the exaggerated pro-inflammatory cytokine responses that characterize IL-10 KO mice and protects against liver damage without altering viral load. IL-10 may be useful to control dysregulated pro-inflammatory cytokines responses during CMV infection.

Keywords MCMV - Pro-inflammatory cytokines · IL-10 · IL-10 deficient · Repletion · Viral load

\section{Introduction}

Interleukin-10 (IL-10) is a pleotrophic, immunomodulatory cytokine with anti-inflammatory and immunosuppressive properties. An important function of IL-10 is to downregulate production of Th1-derived pro-inflammatory cytokines (including IFN- $\gamma$ and TNF- $\alpha$ ) and to inhibit T-cell proliferation [1-3]. Pro-inflammatory cytokines are an essential part of the host response to viral infections. For example, murine cytomegalovirus (MCMV) infection induces a pro-inflammatory cytokine response characterized by production of IFN- $\gamma$, TNF- $\alpha$, IL- $1 \alpha$, IL- $1 \beta$ and IL- 6 that occurs at the organ level as well as systemically [4-7]. Even though this response is necessary for viral control and clearance, an excessive production of pro-inflammatory cytokines can also be detrimental to the host and can result in greater organ damage with increased morbidity and mortality.

Studies in IL-10 deficient mice have shown that these mice suffer more severe MCMV disease than do the wild type background strain. Oakley et al. [8] reported that IL-10 knockout (IL-10 KO) mice experience more 
morbidity than their wild type counterparts and hypothesized that this was due to uncontrolled production of proinflammatory cytokines, particularly IFN- $\gamma$ and IL-6. In those experiments, depletion of IFN- $\gamma$ did not reduce the severity or affect the progression of CMV disease. Other studies in MCMV-infected IL-10 KO mice showed that infection of the brain led to lethal disease due to a dysregulated production of IFN- $\gamma$ and IFN- $\gamma$-inducible chemokines, CXCL9 and CXCL10, as well as IL-6 [9, 10].

Recent studies suggest that IL-10 polymorphisms may be linked to the risk for human CMV infection after transplantation and/or to CMV disease severity. Certain IL-10 genotypes (particularly SNPs at position -1082) are associated with low or high expression of IL-10 [11]. Alakulppi et al. [12] reported that kidney transplant recipients with high IL-10 expression genotypes receiving organs from donors with low IL-10 expression genotypes did not develop CMV disease, suggesting that the recipient IL-10 production may be associated with decreased risk of CMV disease [12].

Furthermore, a number of studies indicate that IL-10 treatment may be therapeutically beneficial in conditions where pro-inflammatory cytokine responses are excessive. Experimental evidence suggests the therapeutic usefulness of IL-10 to downregulate inflammation in chronic gastrointestinal inflammatory diseases such as Crohn's disease and ulcerative colitis [13, 14]. IL-10 treatment has also shown benefits in experimental models of autoimmune diseases including psoriasis, rheumatoid arthritis, and multiple sclerosis [15-17]. In regards to viral infections, IL-10 has been used to treat myocarditis induced by encephalomyocarditis virus (EMCV) and stromal keratitis caused by herpes simplex virus in mouse models with some encouraging results $[18,19]$.

Based on these observations, we hypothesized that IL-10 repletion in MCMV-infected IL-10 KO mice would result in suppression of pro-inflammatory cytokines and consequent reduction of clinical CMV disease. Mouse recombinant IL-10 (mrIL-10) was administered intraperitoneally to MCMV-infected IL-10 KO mice. Our results showed that IL-10 repletion therapy, as described in this study, suppressed pro-inflammatory cytokines without altering viral replication, and resulted in some attenuation of clinical signs of disease and less organ pathology in MCMV-infected IL-10 KO mice.

\section{Materials and methods}

Mice

Pathogen free-female 6-7-week-old IL-10 KO mice were purchased from Jackson Laboratories (Bar Harbor, ME,
USA). Six to seven-week-old female C57BL/6 mice were obtained from Harlan Sprague-Dawley (Indianapolis, IN, USA). All mice were housed in American Association for Assessment and Accreditation of Laboratory Animal Care (AAALAC)-approved specific pathogen-free (SPF) facilities at our institution and had free access to food and water. Animal studies and protocols were approved by the University of California, Davis Institutional Animal Care and Use Committee (IACUC).

Virus and infection

The Smith strain of MCMV was obtained from American Type Culture Collection (ATCC) (Manassas, VA, USA) and maintained by salivary gland passage in BALB/c mice. Salivary gland homogenates (SGV) were prepared in RPMI 1640 (Gibco Laboratories, Grand Island, NY, USA) as described elsewhere [20]. To determine the sub-lethal dose to establish a clinical infection, a $\mathrm{LD}_{50}$ of the $\mathrm{SVG}$ was performed using standard protocols [20]. Mice were infected intraperitoneally (i.p.) with a sub-lethal dose containing $\sim 10^{5}$ plaque forming units (pfu) of MCMV as determined by the plaque assay [4]. In all studies, controls (uninfected mice) received the same volume $(0.2 \mathrm{ml})$ of RPMI i.p. Mice were observed and scored daily for signs of MCMV disease as follows: 0 : no signs observed; +1 : slightly lethargic, ruffle fur primarily around neck, hunched while sitting; +2 : lethargic, ruffle fur around neck area and torso, backbone prominent when sitting, squinty eyes; +3 : very lethargic, ruffled fur in most areas, red skin around neck area, hunched when walking, more prominent squinty eyes.

Mouse recombinant IL-10 treatment of IL-10 KO mice

Carrier-free mouse recombinant IL-10 (mrIL-10) was obtained from eBioscience (San Diego, CA, USA). mrIL-10 was diluted in phosphate buffer saline (PBS), $\mathrm{pH} 7.2$ (Gibco Laboratories, Grand Island, NY, USA) as recommended by the manufacturer.

\section{Determination of optimal dose of mrIL-10}

Various doses of mrIL-10 were initially used to determine the minimum optimum dose that would allow us to detect the cytokine in mouse serum by enzyme linked immunoassay (ELISA). Doses of 2.5, 5 and $10 \mu \mathrm{g}$ per mouse per day were administered intraperitoneally $(0.2 \mathrm{ml})$ to uninfected IL-10 KO mice. Serum samples were collected and analyzed by ELISA at 4 and $20 \mathrm{~h}$ after administration of mrIL-10.

Baseline levels of pro-inflammatory cytokines in uninfected IL-10 KO mice were very low (IL- $1 \alpha: 7 \mathrm{pg} / \mathrm{ml}$; 
IL-1 $\beta$ : $4.5 \mathrm{pg} / \mathrm{ml}$; IL-6: $4.5 \mathrm{pg} / \mathrm{ml}$; IFN- $\gamma: 3.15 \mathrm{pg} / \mathrm{ml}$; TNF- $\alpha$ : 4 pg/ml). Repletion of IL-10 in uninfected IL-10 KO mice had no observable impact on baseline levels of pro-inflammatory cytokines or on physiological parameters in these mice.

\section{Treatment protocol with mrIL-10}

IL-10 KO mice were infected with a sub-lethal dose of MCMV on day 0 . mrIL-10 was administered in a dose of $5 \mu \mathrm{g}(0.2 \mathrm{ml}$, optimum dose) i.p. per mouse per day for five consecutive days starting at day 0 . Another group of MCMV-infected IL-10 KO mice received $0.2 \mathrm{ml}$ of PBS i.p. per day for 5 consecutive days instead of mrIL-10.

Nucleic acid extraction and cDNA synthesis

At days $0,1,3,5$ and 8 post-infection, groups of mice $(n=8)$ were killed by terminal anesthesia and samples of livers and spleens were removed and placed in Nucleic Acid Purification Lysis solution (Applied Biosystems, Foster City, CA, USA) for RNA extraction.

RNA extraction and cDNA synthesis were performed at the Molecular Core Facility, School of Veterinary Medicine at our institution using the 6700 RNA extraction apparatus (Applied Biosystems, Foster City, CA, USA) as described elsewhere [5]. DNA was extracted from each organ with the DNeasy Tissue Kit (Qiagen, Valencia, CA, USA) following the manufacturer's instructions.

Cytokine and chemokine transcription in target organs using real-time PCR

Transcription of IL- $1 \alpha$, IL- $1 \beta$, IL- 6 , IFN- $\gamma$, TNF- $\alpha$, and CXCL9 and CXCL10, as well as transcription of the housekeeping genes GAPDH and HPRT, was determined by quantitative real-time PCR (qRT-PCR) using the Assay on Demand kits (Applied Biosystems, Foster City, CA, USA) with the respective primers/fluorogenic probe mix specific for each cytokine/chemokine gene. Briefly, realtime PCR reactions were set up in duplicate for each of the cytokines, chemokines and housekeeping genes in each organ. Amplification conditions were identical for all reactions and consisted of $2 \mathrm{~min}$ at $50^{\circ} \mathrm{C}, 10 \mathrm{~min}$ at $95^{\circ} \mathrm{C}$ and 40 cycles of $15 \mathrm{~s}$ at $95^{\circ} \mathrm{C}$ and $60 \mathrm{~s}$ at $60^{\circ} \mathrm{C}$. All reactions were prepared in a final volume of $6 \mu \mathrm{l}$ consisting of $3.5 \mu \mathrm{l}$ of Universal Master mix (Applied Biosystems, Foster City, CA, USA) containing the respective primer/ probe mix and $2.5 \mu \mathrm{l}$ of cDNA. Amplifications were done in 384-well plate format in an ABI Prism 7900 Sequence Detection System (Applied Biosystems, Foster City, CA, USA).
Final quantification was performed using the comparative $C_{\mathrm{T}}$ method as described $[5,21]$. In brief, for each experimental sample, the difference between the target $C_{\mathrm{T}}$ value and the $C_{\mathrm{T}}$ value of the most stable housekeeping gene for each tissue type was used to normalize for differences in the amount of total nucleic acid added to each reaction and the efficiency of the RT step $\left(\Delta C_{\mathrm{T}}\right)$. For relative quantification by the comparative $C_{\mathrm{T}}$ method, values are then expressed relative to a reference sample called the calibrator, which is the weakest signal from the normalization $\left(\Delta C_{\mathrm{T}}\right)$ in each tissue type. The $\Delta C_{\mathrm{T}}$ from each experimental sample was subtracted from the $\Delta C_{\mathrm{T}}$ of the calibrator $\left(\Delta \Delta C_{\mathrm{T})}\right.$. The amount of target (linear value) normalized to an internal control or housekeeping gene and relative to the calibrator was determined by $2^{\Delta \Delta C}$. Linear expression in each tissue represents the linear expression value of each gene in infected mice minus that in uninfected mice (baseline or day 0 ).

Assay of cytokine levels in sera of IL-10 KO mice by ELISA

At the time points indicated above, blood was collected by cardiac puncture and allowed to clot, and serum was collected by centrifugation and stored at $-20^{\circ} \mathrm{C}$. Serum levels of IL- $1 \alpha$, IL- $1 \beta$, IL- 6 , IL-10, IFN- $\gamma$, and TNF- $\alpha$ were assayed using the 6-Plex Mouse Cytokine Panel in a Bioplex plate reader (BioRad Laboratories, Hercules, CA, USA). Assays were performed in duplicate on serum samples from eight mice per time point. All assays were performed following the manufacturer's recommendations.

Assay of viral load in target organs by quantitative real time PCR and plaque assay

MCMV viral load was quantified as previously described [5]. Amplification and cloning of the MCMV immediate early gene 1 (IE-1), sequences of the primers and fluorogenic probe, amplification conditions and final quantification are described elsewhere [5]. Plaque assays were performed using standard protocols as previously described [4].

\section{Liver histopathology}

Samples of livers and spleens were fixed in $4 \%$ paraformaldehyde in PBS and paraffin embedded using standard protocols. Six micrometer thick paraffin embedded sections of livers and spleens were deparafinized and hydrated through graded alcohol washes. Hematoxylin and Eosin (H\&E) staining of paraffin-embedded sections of livers and spleens from MCMV infected IL-10 KO and C57BL/6 mice were done according to standard protocols. The 
histology activity index (HAI-Knodell Score) was used to score liver pathology (Table 1) [22, 23].

Statistical analyses

To compare the cytokine response and viral load between mrIL-10 treated and untreated mice, two sample $t$ tests were used separately for each cytokine in each organ at each of the time points analyzed; $95 \%$ confidence intervals for the difference in means were calculated. Data were plotted to check for normality and non-parametric alternative procedures (Wilcoxon rank sum test) were carried out if the data suggested possible violations of distribution assumptions after log transformation. Results were considered statistically significant when $p \leq 0.05$. Analyses were performed using SAS Version 9.1 (SAS) statistical software.

\section{Results}

Determination of mrIL-10 levels in serum of IL-10 KO mice

To determine the time course for systemic distribution of IL-10 and the optimum dose to use in our studies, uninfected IL-10 KO mice were treated with various doses of mrIL-10 and serum levels of IL-10 were assessed at 4 and $20 \mathrm{~h}$ after treatment. Significant levels of IL-10 were detectable in sera of mice receiving $2.5,5$ and $10 \mu \mathrm{g}$ of mrIL-10 after $4 \mathrm{~h}$ (average of 3,457, 9,705 and 20,152 pg/ml, respectively, for each dose). By $20 \mathrm{~h}$ post-treatment, systemic levels of IL-10 had decreased 100 to 1,000-fold but were still detectable in mice receiving 5 and $10 \mu \mathrm{g}$ of mrIL-10 (Table 2). Based on these results, all subsequent experiments were performed using a dose of $5 \mu \mathrm{g}$ of mrIL10 for 5 days starting on day 0 (day of infection).
Pro-inflammatory cytokine and chemokine transcription in livers and spleens of IL-10 KO mice treated with mrIL-10 was reduced at day 5 post-infection compared to untreated mice

We hypothesized that repletion of IL-10 in MCMV-infected IL-10 KO mice would inhibit pro-inflammatory cytokines and thus suppress target organ inflammation and tissue damage. Transcription studies using quantitative real-time PCR showed comparable cytokine levels at day 1 (Fig. 1a). By day 3, pro-inflammatory cytokine mRNA levels in livers of MCMV-infected IL-10 treated mice were significantly lower than in untreated mice (Fig. 1b). A significant decrease in IFN- $\gamma(\sim 70$-fold $)$ and TNF- $\alpha$ ( $\sim 50$-fold) mRNA was observed in livers of the MCMVinfected, IL-10 treated mice compared to untreated mice at day 5 post-infection ( $\mathrm{p} \leq 0.05$ ) (Fig. $1 \mathrm{c}$ ). By day 8 postinfection, and after IL-10 treatment was discontinued, transcription patterns in livers were similar in treated and untreated groups (Fig. 1d).

In spleens, comparable pro-inflammatory cytokine transcription was observed in treated and untreated mice at days 1 and 3 post-infection (Fig. 2a, b). However, by day 5 post-infection, mRNA transcripts of IFN- $\gamma$ were $\sim 17$-fold and of IL-6 were $\sim 600$-fold lower in spleens of MCMVinfected, IL-10 treated compared to the untreated mice $(p<0.05)$ (Fig. 2c). Pro-inflammatory cytokine transcription remained lower in spleens at day 8 post-infection, particularly IL- $1 \alpha(p<0.005)$ (Fig. $2 \mathrm{~d})$.

Transcription of IFN- $\gamma$-inducible chemokines CXCL9 and CXCL10 mRNA was $\sim 4$ to 6-fold lower in livers of MCMV-infected, IL-10 treated mice at days 3 to 5 post-infection ( $p<0.005$ ) (Fig. $3 \mathrm{a}, \mathrm{b}$ ), and $\sim 4$ to 6 -fold lower in spleens at day 5 post-infection $(p \leq 0.005)$ (Fig. 3c, d).

As previously reported, pro-inflammatory cytokines were produced in response to MCMV infection in the

Table 1 Liver Histology Activity Index (HAI) [22]

\begin{tabular}{|c|c|c|c|}
\hline Periportal \pm bridging necrosis & $\begin{array}{l}\text { Intralobular degeneration } \\
\text { and focal necrosis }\end{array}$ & Portal inflammation & Fibrosis \\
\hline $0=$ None & $0=$ None & $0=$ None & $0=$ None \\
\hline $1-2=$ Mild piecemeal necrosis & $\begin{array}{l}1-2=\text { Mild (involves }<1 / 3 \\
\text { of lobules or nodules) }\end{array}$ & $\begin{array}{l}1-2=\text { Mild (sprinkling of } \\
\text { inflammatory cells in }<1 / 3 \\
\text { of portal tracts) }\end{array}$ & $\begin{array}{l}1-2=\text { Fibrous } \\
\text { portal expansion }\end{array}$ \\
\hline $\begin{array}{c}3=\text { Moderate piecemeal necrosis (involves }<50 \% \\
\text { of the circumference of most portal tracts) }\end{array}$ & $\begin{array}{l}3=\text { Moderate (involvement } \\
\text { of } 1 / 3-2 / 3 \text { of lobules or nodules) }\end{array}$ & $\begin{array}{l}3 \text { = Moderate (increased } \\
\text { inflammatory cells in 1/3-2/3 } \\
\text { of portal tracts) }\end{array}$ & $\begin{array}{l}3 \text { = Bridging } \\
\text { fibrosis }\end{array}$ \\
\hline $\begin{array}{l}4=\text { Marked piecemeal necrosis (involves }>50 \% \\
\text { of the circumference of most portal tracts) }\end{array}$ & $\begin{array}{l}4=\text { Marked (involvement } \\
\text { of }>2 / 3 \text { of nodules) }\end{array}$ & $\begin{array}{l}4=\text { Marked (dense packing } \\
\text { of inflammatory cells in }>2 / 3 \\
\text { of portal tracts) }\end{array}$ & $4=$ Cirrhosis \\
\hline
\end{tabular}


Table 2 Concentration $(\mathrm{pg} / \mathrm{ml})$ of mrIL-10 in sera of IL-10 KO mice receiving various doses of mrIL-10

\begin{tabular}{llll}
\hline Time after IL-10 injection & Dose: $2.5 \mu \mathrm{g}$ & Dose: $5 \mu \mathrm{g}$ & Dose: $10 \mu \mathrm{g}$ \\
\hline $4 \mathrm{~h}$ & $3,457( \pm 659) \mathrm{pg} / \mathrm{ml}$ & $9,705( \pm 4,127) \mathrm{pg} / \mathrm{ml}$ & $20,152( \pm 6,246) \mathrm{pg} / \mathrm{ml}$ \\
$20 \mathrm{~h}$ & $<11( \pm 4) \mathrm{pg} / \mathrm{ml}$ & $90( \pm 77) \mathrm{pg} / \mathrm{ml}$ & $285( \pm 318) \mathrm{pg} / \mathrm{ml}$ \\
\hline
\end{tabular}

Four IL-10 KO mice were used per time point/per dose

Fig. 1 Cytokine transcription in livers of treated and untreated MCMV-infected IL-10 KO mice at a 1 day post-infection; b 3 days post-infection; c 5 days post-infection; d 8 days post-infection. Data represent average of 8 mice per time point. Linear value $=$ linear value in infected - linear value in uninfected control mice;

*statistically significant difference between treated versus untreated mice represented as $p \leq 0.05$ (Wilcoxon rank sum test)

Fig. 2 Cytokine transcription in spleens of treated and untreated MCMV-infected IL-10 KO mice at a 1 day post-infection; b 3 days post-infection; c 5 days post-infection; $\mathbf{d} 8$ days post-infection. Data represent average of 8 mice per time point. Linear value $=$ linear value in infected - linear value in uninfected control mice; *statistically significant difference between treated versus untreated mice represented as $p \leq 0.05$ (Wilcoxon rank sum test)
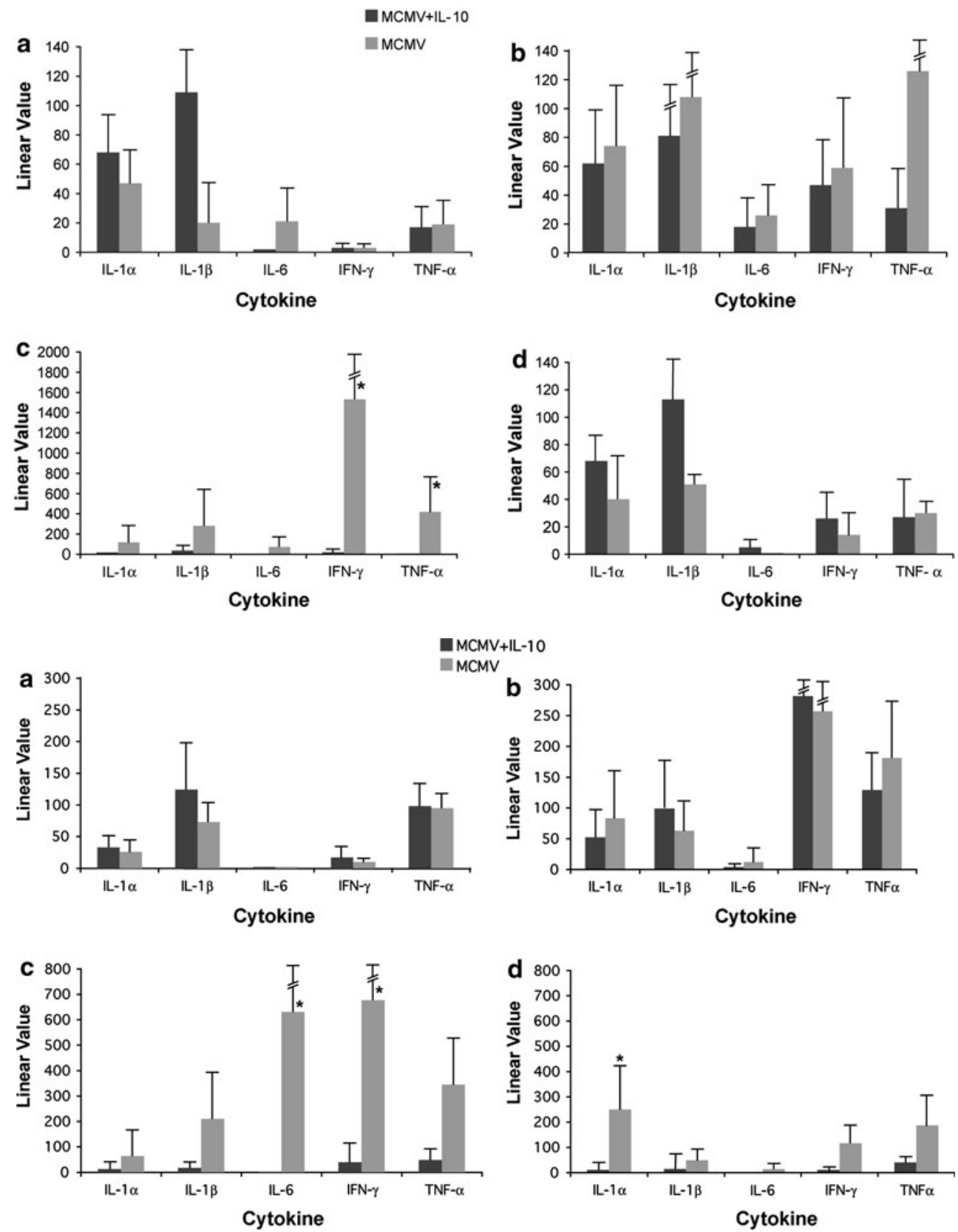

background wild-type strain C57BL/6 mice, with virus induced transcription of IFN- $\gamma, \mathrm{TNF}-\alpha$ and IL-6 starting at day 2 post-infection, which remained elevated until day 5 post-infection, but cytokine levels were significantly lower than in IL-10 KO mice (data not shown).
Serum levels of pro-inflammatory cytokines in IL-10 $\mathrm{KO}$ mice treated with mrIL-10 were lower at day 5 post-infection compared to untreated mice

Comparable levels of serum cytokines were detected in MCMV-infected IL-10 treated and untreated mice at days 1 
Fig. 3 Transcription of CXCL9 and CXCL10 in livers and spleens of MCMV-infected IL10 treated and untreated IL-10 KO mice. $\mathbf{a}, \mathbf{b}$ transcription in livers; $\mathbf{c}, \mathbf{d}$ transcription in spleens. Data represent average of 8 mice per time point. Linear value $=$ linear value in infected - linear value in uninfected control mice; *statistically significant difference between treated versus untreated mice represented as $p \leq 0.05$ (two sample $t$ test)
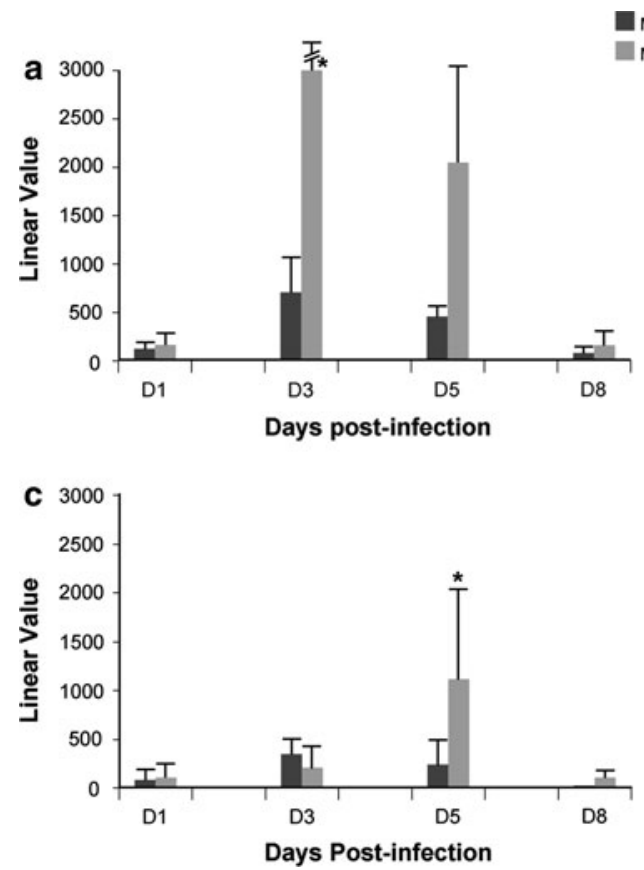
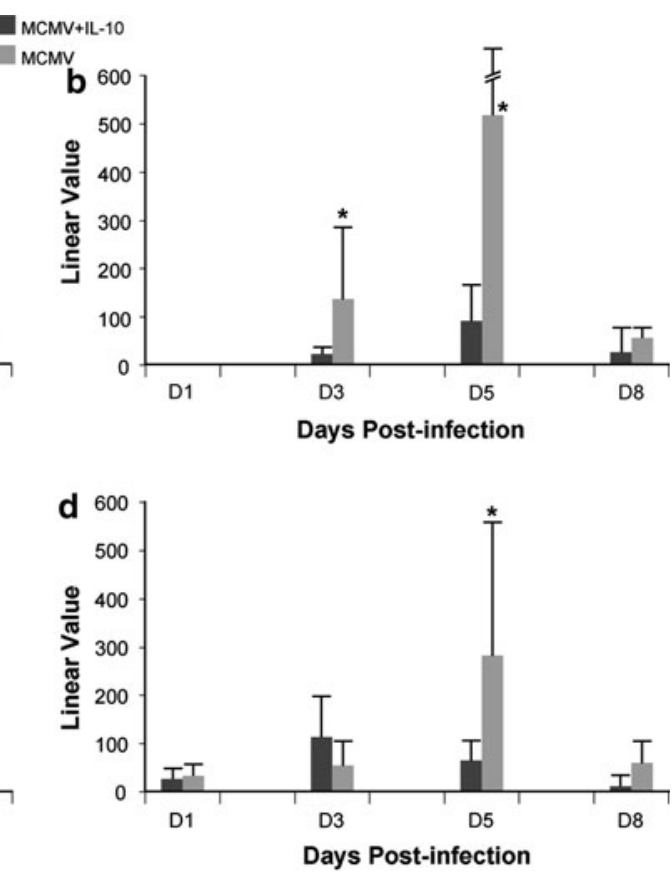

and 3 post-infection (data not shown). By day 5 postinfection, serum levels of IFN- $\gamma$ were significantly lower ( $\sim 10$-fold) in the IL-10 treated compared to the untreated IL-10 KO mice $(p<0.05)$ (Fig. 4).

MCMV viral load was similar in mrIL-10 treated versus untreated IL-10 KO mice

In order to determine if IL-10 treatment had an effect on MCMV, we quantified MCMV IE-1 gene copies in livers and spleens of treated and untreated mice using quantitative real time PCR, as well as viral replication using plaque assay (pfu). Viral loads in both groups of mice peaked at day 3-5 post-infection, with comparable amounts of IE-1

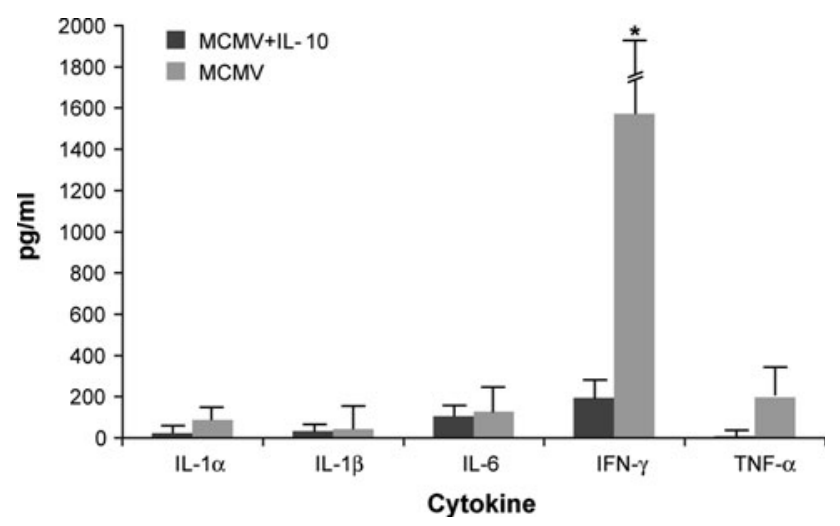

Fig. 4 Cytokine levels in sera of MCMV-infected IL-10 treated and untreated IL-10 KO mice at day 5 post-infection. Data represent average of 8 mice per time point; *statistical significant difference between treated and untreated mice represented as $p \leq 0.05$ (two sample $t$ test) gene sequences in livers and spleens of both treated and untreated mice (Fig. 5). Viral replication studies using plaque assay confirmed the comparable viral load results (data not shown).

MCMV-induced weight loss and liver pathology in mrIL-10 treated versus untreated IL-10 KO mice

Untreated IL-10 KO mice showed a trend toward suffering increased MCMV-induced weight loss compared to mice repleted with mrIL-10 (Fig. 6). By day 3-5 post-infection, percent weight loss was $14 \%$ in the untreated mice compared to $10 \%$ in the IL-10 KO repleted mice $(p=0.08)$. Other clinical signs of CMV disease (lethargy, ruffled fur and hunched posture) were similar in both groups of mice (score of +1$)$.

At day 3 post-infection, more pronounced intralobular degeneration and focal necrosis was observed in livers of untreated versus IL-10 treated mice ( $p=0.04$ ) (Fig. 7a, b, $\mathrm{d}$, e) (Table 3 ). In addition, we observed a trend for lymphocyte infiltration to be greater $(\sim 2$-fold) in livers of untreated versus treated mice at day 5 post-infection ( $p=0.09$ ) (Fig. 7c, f). No pathological findings were observed in spleens of either group of mice (data not shown).

\section{Discussion}

IL-10 deficient mice have increased morbidity from MCMV infection compared to the background strain, 
Fig. 5 Viral load (IE1 gene copies) in livers (a) and spleens (b) of MCMV-infected IL-10 treated and untreated IL-10 KO mice. Data represent average of 8 mice per time point. No significant differences were observed in treated versus untreated mice

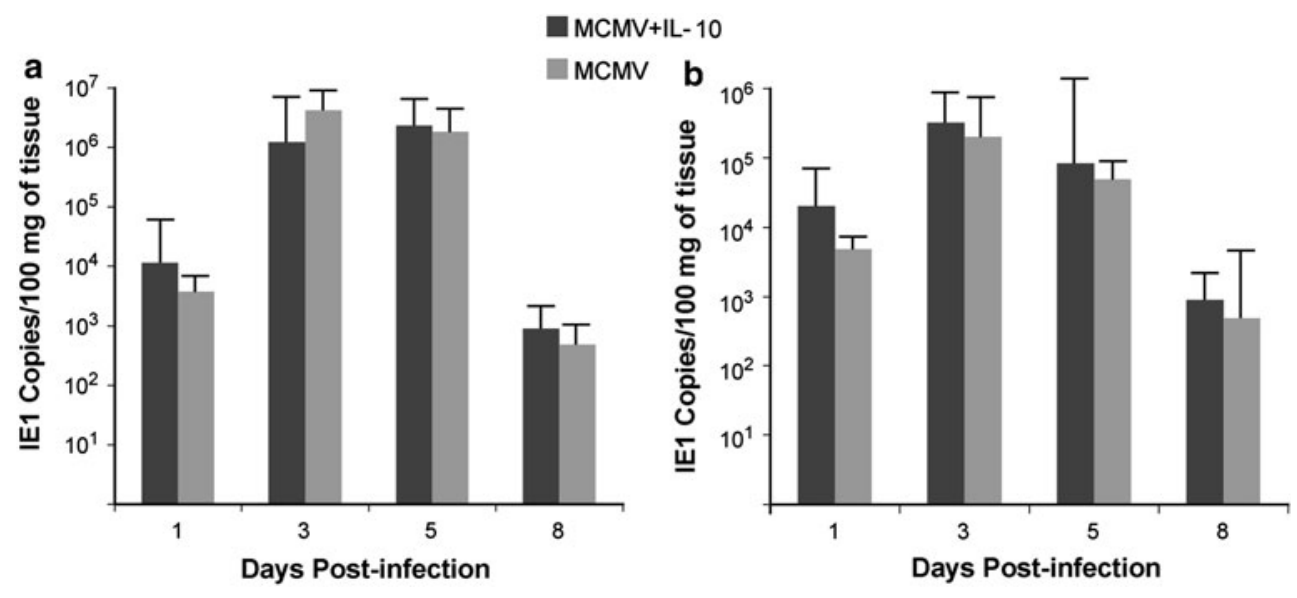

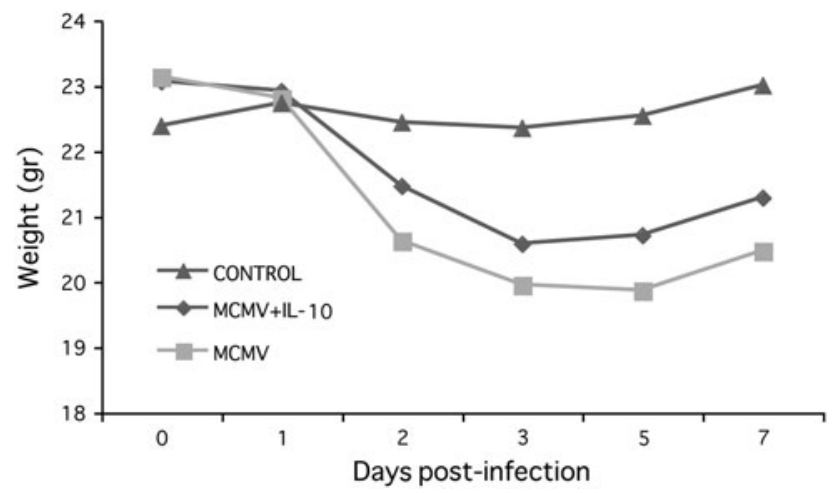

Fig. 6 Weight loss in MCMV-infected IL-10 treated and untreated IL-10 KO mice. Data represent average of 8 mice per time point

C57BL/6 mice $[8,9]$. We hypothesized that in the absence of IL-10, an exaggerated production of pro-inflammatory cytokines, particularly IFN- $\gamma$ and IL-6, rather than increased viral replication, might be responsible for the exacerbated severity of CMV disease. To test this hypothesis, we treated MCMV-infected IL-10 KO mice with IL-10 to see if repletion would inhibit pro-inflammatory responses and what the impact would be on viral load and clinical evidence of CMV disease. We found that the administration of exogenous mrIL-10 over a 5-day period, starting on the day of infection, suppressed IFN- $\gamma$, TNF- $\alpha$ and IL- 6 transcripts in target organs, reduced systemic levels of IFN- $\gamma$ and IL- 6 and decreased production of the IFN- $\gamma$ inducible chemokines CXCL9 and CXCL10 but did not affect MCMV viral load. We also observed beneficial effects of IL-10 repletion on liver pathology with decreased focal necrosis in the liver at day 3 post-infection. Our findings confirmed our hypothesis that IL- 10 repletion in our mouse model of MCMV infection blunts proinflammatory cytokine responses without impacting viral replication.

The therapeutic use of IL-10 in auto-immune and inflammatory diseases has been controversial, with many studies in mouse models showing a beneficial effect $[15$, 17, 24], but others reporting conflicting results [16]. These discrepancies may be attributable to differences in the dose, source, mode and route of delivery of IL-10. In our study, we administered $5 \mu \mathrm{g}$ of murine recombinant IL-10 daily for 5 days by intraperitoneal injection. Levels of IL-10 were detectable in sera of treated mice $20 \mathrm{~h}$ after injection, but they were $\sim 100$-fold lower than initial levels. Our treatment protocol resulted in a significant reduction of pro-inflammatory cytokines (both systemically and at the organ level), particularly after five treatments (day 5 postinfection). The lack of a sustained, continuous and regulated dose of IL-10 during the course of MCMV infection may explain the mild effect of IL-10 on disease severity observed in this study. Studies are in progress in our laboratory using IL-10 expression vectors to deliver sustained and controlled doses of IL-10 in our IL-10 deficient mouse model to determine if a more dramatic impact on clinical disease severity can be demonstrated.

Despite suppressing pro-inflammatory cytokines, exogenous mrIL-10 did not affect viral replication. Proinflammatory cytokines are part of the host response to CMV infection and participate in viral clearance. The finding that viral load was comparable in both groups of mice suggest that IL-10, as used in this study, does not impair the control of $\mathrm{CMV}$, but rather may inhibit local production of pro-inflammatory cytokines by infiltrating lymphocytes in target organs. Our results are in accord with the observations of Nishio et al.[18], that IL-10 treatment of viral myocarditis induced by EMCV suppressed inflammation without altering viral replication, and of Cheeran et al. [9], who reported similar MCMV viral loads in IL-10 deficient mice and in immunocompetent mice, C57BL/6 (which is a model simulated by the IL-10 KO mice repleted with mrIL-10).

Importantly, when considering possible therapeutic use of IL-10 to achieve these benefits, our results demonstrated that IL-10 did not increase MCMV replication in target 
Fig. 7 H\&E stained sections of livers from a MCMV-infected untreated mice at day 3 postinfection $(10 \times)$; b MCMVinfected untreated mice at day 3 post-infection $(20 \times)$; c MCMVinfected untreated mice at day 5 post-infection $(20 \times)$; d MCMVinfected, IL-10 treated mice at day 3 post-infection $(10 \times)$; e MCMV-infected, IL-10 treated mice at day 3 postinfection (20x); f MCMVinfected, IL-10 treated mice at day 5 post-infection $(20 \times)$. Sections are representative of 8 mice per time point. Number of inflammatory foci was increased in the untreated mice $(\mathbf{a}-\mathbf{c})$
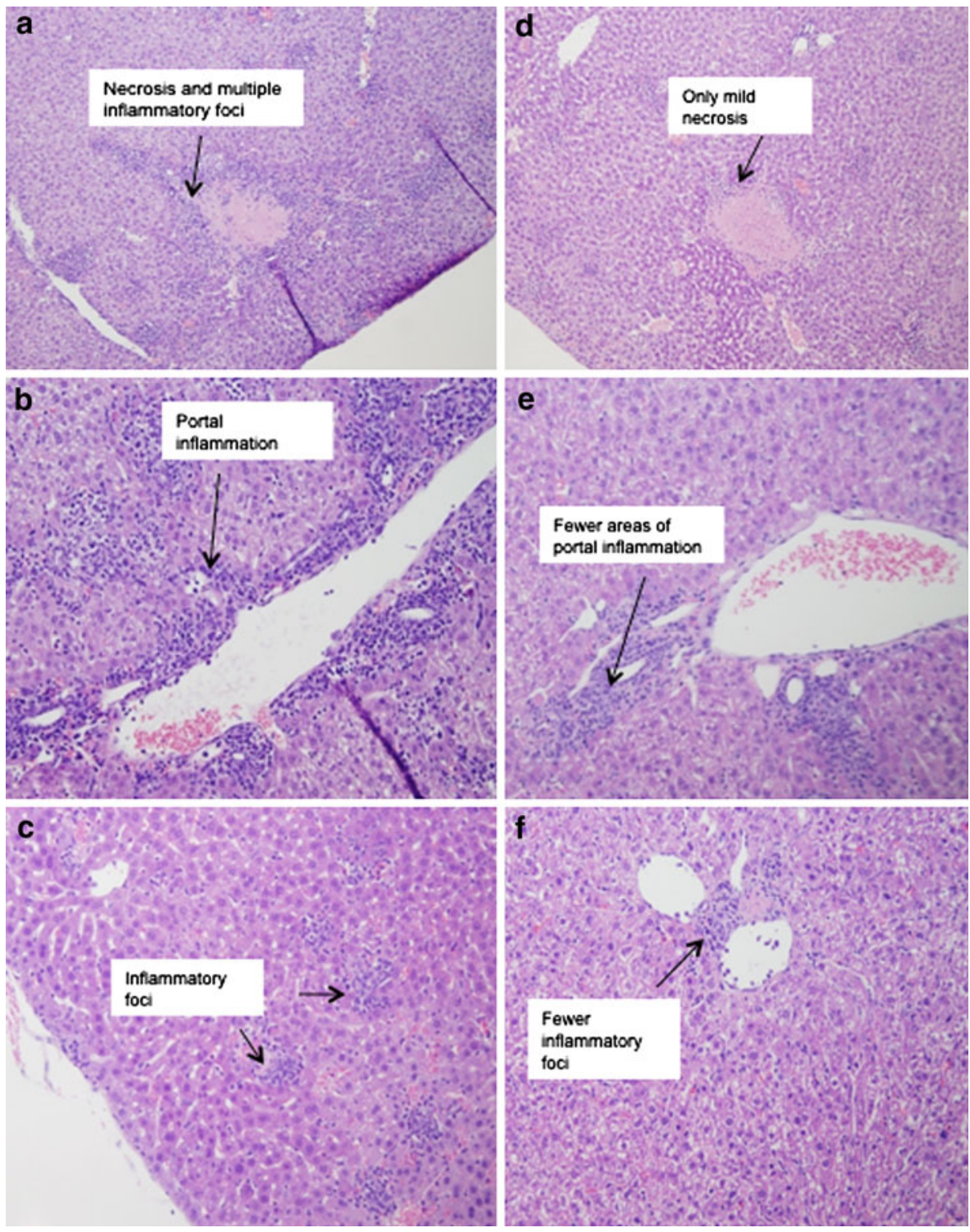

organs and did not delay clearance of MCMV from these organs. This is in contrast to reports with other viral infections in which IL-10 treatment was associated with viral persistence. Such studies include lymphocytic choriomeningitis virus (LCMV) in mice [25] and HIV and hepatitis C (HCV) in humans [26, 27]. On the other hand, some previous studies of other viruses parallel our results, such as the studies of Lin et al. [28] using a neurotrophic strain of mouse hepatitis virus. Lin et al. showed that clearance of the virus in IL-10 deficient and C57BL/6 immunocompetent mice occurred with equal kinetics, and that IL-10 did not delay viral clearance during acute encephalomyelitis with mouse hepatitis virus. Thus, it is likely that the impact of IL-10 on viral load is virus-specific and disease-model specific.

CMV infection is a trigger of pro- inflammatory cytokines and is an identified risk for graft versus host disease
(GVHD) and organ rejection after transplantation. The role that IL-10 plays during CMV infection in transplant recipients is still being actively explored. CMV replication in renal transplant recipients has been associated with increased levels of IL-10 and decreased IFN- $\gamma$ plasma levels [29]. Nordoy et al. [30] showed that CMV infection in renal transplant recipients is characterized by a persistent activation of TNF- $\alpha$ in symptomatic CMV positive patients, while CMV-infected, asymptomatic patients had elevated levels of IL-10. TNF- $\alpha$ is a key factor in reactivating CMV from latency leading to expression of CMV immediate early gene and viral replication [31]. Thus, the balance between TNF- $\alpha$ and IL-10 may be an important factor in the development of clinical disease [30]. Yet, in lung transplant recipients, a prolonged delayed in clearance of HCMV has been associated with elevated levels of IL-10 [32]. Clearly, it is important to distinguish the role of 
Table 3 Average histopathology scores in livers of MCMV-infected IL-10 treated and untreated IL-10 KO mice

\begin{tabular}{|c|c|c|c|c|}
\hline Sample and day of treatment & $\begin{array}{l}\text { Periportal } \pm \text { bridging } \\
\text { necrosis score }\end{array}$ & $\begin{array}{l}\text { Intralobular degeneration } \\
\text { and focal necrosis score }\end{array}$ & $\begin{array}{l}\text { Portal inflammation } \\
\text { score }\end{array}$ & $\begin{array}{l}\text { Fibrosis } \\
\text { score }\end{array}$ \\
\hline \multicolumn{5}{|l|}{ Day 1} \\
\hline MCMV alone & 0 & 0 & 0 & 0 \\
\hline MCMV + IL-10 & 0 & 0 & 0 & 0 \\
\hline \multicolumn{5}{|l|}{ Day 3} \\
\hline MCMV alone & 2 & 3 & 2 & 0 \\
\hline MCMV + IL-10 & $1.5(p=0.14)$ & $1.5(p=0.04)$ & $1(p=0.07)$ & 0 \\
\hline \multicolumn{5}{|l|}{ Day 5} \\
\hline MCMV alone & 2.2 & 2.2 & 2.2 & 0 \\
\hline MCMV + IL-10 & $2(p=0.19)$ & 2 & 2 & 0 \\
\hline \multicolumn{5}{|l|}{ Day 8} \\
\hline MCMV alone & 1.5 & 1.7 & 1.5 & 0 \\
\hline MCMV + IL-10 & $1(p=0.09)$ & $1.5(p=0.39)$ & $1(p=0.09)$ & 0 \\
\hline
\end{tabular}

Scores represent average of pathological lesions in $n=8$ mice per each treatment group (See Table 1 for description of histopathological findings) with statistical significance represented as $p=0.04$ at day 3 (two tailed $t$ test) between mrIL-10 treated and untreated mice

IL-10 in risk of acquiring initial infections versus its production in response to viral-induced pro-inflammatory cytokines as well as its role in limiting disease severity.

The significant increase in intralobular degeneration and focal necrosis in the livers of untreated IL-10 deficient mice at day 3 post-infection correlated with increases in CXCL9 transcripts in livers. CXCL9 and CXCL10 are chemokines involved in promoting $\mathrm{T}$ lymphocyte migration into the liver and have been correlated with hepatic accumulation of MCMV-specific CD8 T-cells [33]. In CMV infected human microgial cells, IL-10 treatment inhibited production of CXCL10 by these cells [34]. We demonstrated that repletion of IL-10 suppresses CXCL9 and CXCL10 production in livers and spleens of MCMVinfected mice. The finding of more severe pathological changes, in the absence of IL-10, in the livers of untreated mice at day 3 post-infection suggests that over-expression of CXCL9 and CXCL10 chemokines resulting in an influx of lymphocytes may have been responsible for the production of pro-inflammatory cytokines and consequent tissue damage.

Thus, in our study, we showed that early repletion (starting at the time of infection) of IL-10 in IL-10 deficient MCMV-infected mice has beneficial effects in control of inflammatory cytokines and chemokines, suppressing production of IFN- $\gamma$, TNF- $\alpha$, IL- 6 , and the IFN- $\gamma$ - inducible chemokines CXCL9 and CXCL10. These findings suggest that immunomodulatory therapy with IL-10 may be useful in preventing or reducing CMV disease severity in high risk patients.

Repletion of IL-10 may be a beneficial immunotherapeutic approach prior to or during organ transplantation. Pre-treatment of lungs (prior to transplantation) with IL-10 has been shown to improve lung function and reduce inflammation [35]. Regulated IL-10 expression inhibits cardiac allograph vasculopathy, reducing the number of graft-infiltrating lymphocytes and macrophages and preventing chronic rejection of transplanted hearts [36]. Similarly, an association has been found between the level of pre-transplant IL-10 production and development of acute GVHD (aGVHD) in allogeneic stem cell transplantation, with increased levels of IL-10 correlating with low incidence of aGVHD [37, 38]. Additionally, overproduction of IL-10 has been linked to the development of tolerance in severe combined immunodeficient patients transplanted with HLA mismatched hematopoietic stem cells [37, 39], and high levels of IL-10 have been associated with induction and maintenance of tolerance after allogeneic stem cell transplantation [39]. Thus, our study extends the reports suggesting the use of IL-10 as a potential tool to treat inflammatory conditions, including viral infections in which an exaggerated pro-inflammatory cytokine response has detrimental end-organ effects. Furthermore, IL-10 treatment early during the at-risk period may be an important therapeutic approach to explore for transplant and other immunocompromised patients with IL-10 polymorphisms resulting in under-expression of IL- 10 .

In conclusion, we found that administration of exogenous mrIL-10 to replete cytokine levels in IL-10 KO mice modulates pro-inflammatory cytokine responses to MCMV infection at the organ level and systemically, independent of an effect on viral load. Our studies expand the current understanding of the role of IL-10 in CMV infection demonstrating that IL-10 is a key regulatory cytokine with immunotherapeutic properties, and raise the possibility that 
the administration of this cytokine may be useful to control dysregulated pro-inflammatory responses during CMV disease. Studies are in progress in our laboratory to define molecular mechanisms by which IL-10 exerts its antiinflammatory effect during MCMV infection.

Acknowledgments The authors thank the Lucy Whittier Molecular Core Facility at the School of Veterinary Medicine, UC Davis, for excellent technical assistance with the RNA extraction and cDNA synthesis. We are grateful to Ms. Maggie Chiu (Department of Medical Pathology and Laboratory Medicine) for technical assistance with the histology portion of this work, and to Ms. Judy Li for statistical analyses. This publication was made possible in part by Grant Number UL1 RR024146 from the National Center for Research Resources (NCRR), a component of the National Institutes of Health (NIH), and NIH Roadmap for Medical Research.

Open Access This article is distributed under the terms of the Creative Commons Attribution Noncommercial License which permits any noncommercial use, distribution, and reproduction in any medium, provided the original author(s) and source are credited.

\section{References}

1. Opal SM, DePalo VA. Anti-inflammatory cytokines. Chest. 2000;117:1162-72.

2. Howard M, O'Garra A. Biological properties of interleukin 10. Immunol Today. 1992;13:198-200.

3. Clarke CJ, Hales A, Hunt A, Foxwell BM. IL-10-mediated suppression of TNF-alpha production is independent of its ability to inhibit NF kappa B activity. Eur J Immunol. 1998;28:1719-26.

4. Pomeroy C, Delong D, Clabots C, Riciputi P, Filice GA. Role of interferon-gamma in murine cytomegalovirus infection. $\mathrm{J}$ Lab Clin Med. 1998;132:124-33.

5. Tang-Feldman YJ, Wojtowicz A, Lochhead GR, Hale MA, Li Y, Pomeroy C. Use of quantitative real-time PCR (qRT-PCR) to measure cytokine transcription and viral load in murine cytomegalovirus infection. J Virol Methods. 2006;131:122-9.

6. Shanley JD, Goff E, Debs RJ, Forman SJ. The role of tumor necrosis factor-alpha in acute murine cytomegalovirus infection in BALB/c mice. J Infect Dis. 1994;169:1088-91.

7. Ritter JT, Tang-Feldman YJ, Lochhead GR, Estrada M, Lochhead $\mathrm{S}, \mathrm{Yu} \mathrm{C}$, Ashton-Sager A, Tuteja D, Leutenegger C, Pomeroy C. In vivo characterization of cytokine profiles and viral load during murine cytomegalovirus-induced acute myocarditis. Cardiovasc Pathol. 2010;19:83-93.

8. Oakley OR, Garvy BA, Humphreys S, Qureshi MH, Pomeroy C. Increased weight loss with reduced viral replication in interleukin-10 knock-out mice infected with murine cytomegalovirus. Clin Exp Immunol. 2008;151:155-64.

9. Cheeran MC, Hu S, Palmquist JM, Bakken T, Gekker G, Lokensgard JR. Dysregulated interferon-gamma responses during lethal cytomegalovirus brain infection of IL-10-deficient mice. Virus Res. 2007;130:96-102.

10. Cheeran MC, Mutnal MB, Hu S, Armien A, Lokensgard JR. Reduced lymphocyte infiltration during cytomegalovirus brain infection of interleukin-10-deficient mice. J Neurovirol. 2009;1-9.

11. Suarez A, Castro P, Alonso R, Mozo L, Gutierrez C. Interindividual variations in constitutive interleukin-10 messenger RNA and protein levels and their association with genetic polymorphisms. Transplantation. 2003;75:711-7.
12. Alakulppi NS, Kyllonen LE, Salo HM, Partanen J, Salmela KT, Laine JT. The impact of donor cytokine gene polymorphisms on the incidence of cytomegalovirus infection after kidney transplantation. Transpl Immunol. 2006;16:258-62.

13. Lindsay JO, Sandison A, Cohen P, Brennan FM, Hodgson HJ. IL-10 gene therapy is therapeutic for dextran sodium sulfate-induced murine colitis. Dig Dis Sci. 2004;49:1327-34.

14. Li MC, He SH. IL-10 and its related cytokines for treatment of inflammatory bowel disease. World J Gastroenterol. 2004;10: $620-5$.

15. Walmsley M, Katsikis PD, Abney E, Parry S, Williams RO, Maini RN, Feldmann M. Interleukin-10 inhibition of the progression of established collagen-induced arthritis. Arthritis Rheum. 1996;39:495-503.

16. Brennan FM. Interleukin 10 and arthritis. Rheumatology (Oxford). 1999;38:293-7.

17. Asadullah K, Sterry W, Stephanek K, Jasulaitis D, Leupold M, Audring H, Volk HD, Docke WD. IL-10 is a key cytokine in psoriasis. Proof of principle by IL-10 therapy: a new therapeutic approach. J Clin Invest. 1998;101:783-94.

18. Nishio R, Matsumori A, Shioi T, Ishida H, Sasayama S. Treatment of experimental viral myocarditis with interleukin-10. Circulation. 1999;100:1102-8.

19. Tumpey TM, Elner VM, Chen SH, Oakes JE, Lausch RN. Interleukin-10 treatment can suppress stromal keratitis induced by herpes simplex virus type 1. J Immunol. 1994;153:2258-65.

20. Pomeroy C, Hilleren PJ, Jordan MC. Latent murine cytomegalovirus DNA in splenic stromal cells of mice. J Virol. 1991;65: 3330-4.

21. Kipar A, Leutenegger CM, Hetzel U, Akens MK, Mislin CN, Reinacher M, Lutz H. Cytokine mRNA levels in isolated feline monocytes. Vet Immunol Immunopathol. 2001;78:305-15.

22. Knodell RG, Ishak KG, Black WC, Chen TS, Craig R, Kaplowitz N, Kiernan TW, Wollman J. Formulation and application of a numerical scoring system for assessing histological activity in asymptomatic chronic active hepatitis. Hepatology. 1981;1: 431-5.

23. Desmet VJ.Knodell RG, Ishak KG, Black WC, Chen TS, Craig R, Kaplowitz N, Kiernan TW, Wollman J. Formulation and application of a numerical scoring system for assessing histological activity in asymptomatic chronic active hepatitis [Hepatology 1981;1:431-435]. J Hepatol. 2003;38:382-6.

24. Lindsay JO, Ciesielski CJ, Scheinin T, Hodgson HJ, Brennan FM. The prevention and treatment of murine colitis using gene therapy with adenoviral vectors encoding IL-10. J Immunol. 2001;166:7625-33.

25. Brooks DG, Trifilo MJ, Edelmann KH, Teyton L, McGavern DB, Oldstone MB. Interleukin-10 determines viral clearance or persistence in vivo. Nat Med. 2006;12:1301-9.

26. Clerici M, Wynn TA, Berzofsky JA, Blatt SP, Hendrix CW, Sher A, Coffman RL, Shearer GM. Role of interleukin-10 in T helper cell dysfunction in asymptomatic individuals infected with the human immunodeficiency virus. J Clin Invest. 1994;93:768-75.

27. Brady MT, MacDonald AJ, Rowan AG, Mills KH. Hepatitis C virus non-structural protein 4 suppresses Th1 responses by stimulating IL-10 production from monocytes. Eur J Immunol. 2003;33:3448-57.

28. Lin MT, Hinton DR, Parra B, Stohlman SA, van der Veen RC. The role of IL-10 in mouse hepatitis virus-induced demyelinating encephalomyelitis. Virology. 1998;245:270-80.

29. Sadeghi M, Daniel V, Naujokat C, Schnitzler P, Schmidt J, Mehrabi A, Zeier M, Opelz G. Dysregulated cytokine responses during cytomegalovirus infection in renal transplant recipients. Transplantation. 2008;86:275-85.

30. Nordoy I, Muller F, Nordal KP, Rollag H, Lien E, Aukrust P, Froland SS. The role of the tumor necrosis factor system and 
interleukin-10 during cytomegalovirus infection in renal transplant recipients. J Infect Dis. 2000;181:51-7.

31. Zamora MR. Cytomegalovirus and lung transplantation. Am J Transplant. 2004;4:1219-26.

32. Zedtwitz-Liebenstein K, Jaksch P, Wulkersdorfer B, Friehs H, Pempelfort SD, Burgmann H, Frass M. Usefulness of interleukin10 detection in lung transplant patients with human cytomegalovirus infection with respect to virus persistence. Transplantation. 2007;84:268-71.

33. Hokeness KL, Deweerd ES, Munks MW, Lewis CA, Gladue RP, Salazar-Mather TP. CXCR3-dependent recruitment of antigenspecific $\mathrm{T}$ lymphocytes to the liver during murine cytomegalovirus infection. J Virol. 2007;81:1241-50.

34. Cheeran MC, Hu S, Sheng WS, Peterson PK, Lokensgard JR. CXCL10 production from cytomegalovirus-stimulated microglia is regulated by both human and viral interleukin-10. J Virol. 2003;77:4502-15.

35. Cypel M, Liu M, Rubacha M, Yeung JC, Hirayama S, Anraku M, Sato M, Medin J, Davidson BL, de Perrot M, Waddell TK, Slutsky AS, Keshavjee S. Functional repair of human donor lungs by IL-10 gene therapy. Sci Transl Med 2009;1:4ra9.
36. Fischbein MP, Yun J, Laks H, Irie Y, Oslund-Pinderski L, Fishbein MC, Bonavida B, Ardehali A. Regulated interleukin-10 expression prevents chronic rejection of transplanted hearts. J Thorac Cardiovasc Surg. 2003;126:216-23.

37. Holler E, Roncarolo MG, Hintermeier-Knabe R, Eissner G, Ertl B, Schulz U, Knabe H, Kolb HJ, Andreesen R, Wilmanns W. Prognostic significance of increased IL-10 production in patients prior to allogeneic bone marrow transplantation. Bone Marrow Transplant. 2000;25:237-41.

38. Wang XN, Lange C, Schulz U, Sviland L, Eissner G, Oliver KM, Jackson GH, Holler E, Dickinson AM. Interleukin-10 modulation of alloreactivity and graft-versus-host reactions. Transplantation. 2002;74:772-8.

39. Bacchetta R, Bigler M, Touraine JL, Parkman R, Tovo PA, Abrams J, de Waal Malefyt R, de Vries JE, Roncarolo MG. High levels of interleukin 10 production in vivo are associated with tolerance in SCID patients transplanted with HLA mismatched hematopoietic stem cells. J Exp Med. 1994;179:493-502. 